\title{
Makna Simbol-Simbol Budaya Dalam Karungut Antang Ngambun Bagi Kehidupan Suku Dayak Ngaju Kalimantan Tengah
}

\author{
Febri Irawan ${ }^{1,}$ Fera Laras Dharmayanti, ${ }^{2}$, Rizki Putri Hanafi ${ }^{3}$. \\ Pendidikan Bahasa dan Sastra Indonesia Fakultas Keguruan dan Ilmu Pendidikan \\ Universitas Muhammadiyah Malang \\ Email: febriirawann@gmail.com, feralarasd@gmail.com,putririzki128@yahoo.com
}

Keywords :

makna, simbol, karungut Antang Ngambun

\begin{abstract}
Penelitian ini mengkaji makna simbol dalam Karungut Antang Ngambun menjelaskan tentang (1) petanda (2) Penanda yang mencakup makna simbol-simbol budaya dalam Karungut Antang Ngambun bagi kehidupan suku Dayak Ngaju Kalimantan Tengah yang bertujuan memberi pengetahuan mengenai makna yang terkandung dalam kebudayaan masyarakat Kalimantan pada zaman nenek moyang yang berisi petuah-petuah kehidupan yang sangat berpengaruh bagi kehidupan sosial masyarakat sekarang. Adapun metode yang digunakan dalam penelitian ini yaitu metode fenomenologi. Pendekatan yang digunakan dalam penelitian ini yaitu pendekatan semiotika Ferdinand De Saussure. Sumber data yang digunakan berupa audio dari informan yang berasal dari suku Dayak Ngaju Kalimantan Tengah. Hasil penelitian yang telah diteliti menjelaskan bahwa banyak sekali simbol makna yang terselubung didalam Karungut Antang Ngambung yang meliputi simbol kelemah lembutan, simbol kasih sayang, simbol sikap pantang menyerah, simbol kepercayaan dan simbol budaya.
\end{abstract}




\section{PENDAHULUAN}

Satra lisan merupakan sebuah karya sastra yang berkembang dalam masyarakat, yang tanpa melibatkan tulisan dalam praktiknya atau dalam kata lain, sistem pewarisannya adalah dari mulut kemulut . Sastra lisan biasa berkembang pada masyarakat yang belum mengenal tulisan atau dalam masyarakat yang sudah mengenal tulisan saat tradisi lisan sudah berkembang dalam masyarakatnya. Menurut (Danandjaja dalam Satriana, 2015: 3 ; Zaidan dalam Faridah, 2016: 23 ; Hutomo dalam Wahyuni, 2016 : 98) sastra lisan adalah kesusastraan yang menggambarkan ekspresi dari warga yang menganut suatu kebudayaan yang disebarkan dari mulut ke mulut". Sastra lisan yang merupakan sastra yang menggambarkan kehidupan pada masa lampau dikarenakan proses penyebarannya berasal dari mulut ke mulut. Bahasa lisan yang digunakan manusia bertujuan untuk membangun kesadaran dirinya dan tingkah laku pada dirinya.

Dalam masyarakat Kalimantan, sastra lisan juga berkembang dengan baik. Salah satu bentuk dari sastra lisan masyarakat Kalimantan adalah Karungut. Karungut merupakan bentuk kebudayaan masyarakat Kalimantan yang disebarkan secara lisan. Krungut merupakan puisi lama yang diungkapkan menggunakan media musik dengan alat berupa kecapi. Masyarakat Dayak menggunakan Karungut sebagai sarana hiburan, yang dilakukan dalam upacara adat maupun keseharian masyarakat. Menurut Andianto (dalam Taruna, 2016: 1-2) karungut adalah kesenian tradisional yang berasal dari suku Dayak Kalimantan yang berupa sebuah nyanyian pada zaman dahulu yang menggunakan bahasa Sangiang berfungsi menyampaikan cerita rakyat yang menceritakan tokoh legendaris. Pada saat ini, karungut dilafalkan mengunakan bahasa Ngaju, sebab bahasa Sangiang mulai hilang terkikis zaman dan sulit dipahami.

Karungut berisi mengenai kisah kehidupan sosial masyarakat dayak, petuah, dan kepercayaan yang dianut masyarakat. Dalam satu judul karungut kebanyakan hanya mengandung satu aspek nilai. Namun ada beberapa yang mengandung dua nilai sekaligus, seperti mengandung petuah dan kepercayaan masyarakat. Karungut Antang Ngambun adalah salah satu dari sekian banyak judul dalam karungut. Karungut Antang ngambun sangat menarik untuk dikaji sebab di dalamnya diceritakan mengenai kehidupan masyarakat Dayak Ngaju. Selain itu, di dalamnya juga berisi tentang kepercayaan masyarakat Dayak Ngaju mengenai sosok yang diagungkan orang-orang Dayak Ngaju.

Karungut Antang Ngambun dilafalkan oleh masyarakat dalam acara adat perikahan, karena di dalamnya berisikan mengenai kasih sayang dan pengorbanan. Selain dalam pernikahan, karungut Antang Ngambun juga sering dilafalkan dalam keseharian masyarakat saat bekerja atau bersantai. Karungut yang merupakan tradisi lisan, berisi mengenai kehidupan dan kepercayaan masyarakat dayak selaras dengan pendapat yang dikemukakan Ricoeur (dalam Faruk, 2014: 45-46) yang menyatakan bahwa "karya sastra sebenarnya dapat dibawa ke dalam keterkaitan yang kuat dengan dunia sosial tempat dan waktu bahasa yang digunakan oleh karya sastra itu hidup dan berlaku". Jadi Karungut Antang ngambun yang notabene adalah sastra lisan, bisa dijadikan salah satu alat untuk menilik kehidupan masa lampau masyarakat Dayak ngaju.

Penelitian ini penting dilakukan karena Karungut ini digunakan sebagai sarana pendidikan moral dan penyampai kepercayaan leluhur terhadap budaya yang mereka pegang. Dalam penelitian ini akan mencari makna dala karungut Antang Ngambun ini, mengingat masyarakat Kalimantan tengah saat ini banyak yang melupakannya. Hal itu terjadi sebab, bahasa Dayak Ngaju dianggap rumit dan sulit dipahami.

Penelitian ini penting untuk dilakukan, sebab setelah membedah arti dan makna, akan dikaitkan dengan makna simbol-simbol budaya dalam Karungut Antang Ngambun ini bagi masyarakat Kalimantan Tengah. Hal ini dapat dilakukan sebab, Karungut berisi mengenai petuah-petuah 
atau penggambaran sosok yang dijadikan panutan yang di sampaikan melalui tradisi lisan. Hal ini diperkuat dengan sangat sulitnya mencari naskah tertulis mengenai karungut ini. Ini menjadi suatu isyarat bahwa karungut hingga saat ini masih menjadi tradisi lisan dalam arti sebenarnya dan dapat menggambarkan tentang kehidupan sosial masyarakat pada masa lalu. Tujuan utama dalam meneliti Karungut Antang Ngambun yaitu untuk memberi pengetahuan mengenai makna yang terkandung dalam kebudayaan masyarakat Kalimantan pada zaman nenek moyang yang berisi petuah-petuah kehidupan yang sangat berpengaruh bagi kehidupan sosial masyarakat sekarang.

Penelitian mengenai karungut Antang ngambun ini, sebelumnya belum pernah dilakukan. Disimpulkan demikian sebab, peneliti telah melakukan observasi mengenai objek kajian, dan tidak ditemukan mengenai penelitian dengan judul serupa. Kebanyakan peneliti terdahulu, mengkaji karungut dari aspek yang lebih luas, seperti pengklasifikasian judul dalam karungut dan penelitian umum mengenai tradisi lisan masnyarakat Kalimantan ini.

Penelitian ini menghasilkan produk yang orisinil, karena penelitian tentang karungut Antang ngambun ini baru pertama kali dilakukan. Meskipun banyak penelitian terdahulu yang mengkaji mengenai karungut, tetapi belum ada yang meneliti mengenai karungut Antang ngambun ini. Dengan demikian penelitian mengenai karungut Antang ngambun ini masih bisa dilakukan dari banyak perspektif, namun pada penelitian kali ini akan difokuskan pada pemaknaan simbolsimbol budaya yang ada dalam Karugut Antang Ngambun.

Dalam penelitian ini teori yang akan digunakan adalah teori semiotik Ferdinand De Saussure. Dijelaskan jika teori semiotika merupakan teori yang mempelajari tentang tanda-tanda dalam karya sastra. Tanda tersebut memiliki tujuan sebagai alat komunikasi dalam menyampaikan suatu informasi penting yang terselubung didalam sebuah karya sastra yang akan diteliti (Tinarbuko, 2003: 33). Tanda sendiri merupakan sarana dalam menguak makna yang tidak tersampaikan oleh pembaca agar pembaca lebih paham dengan maksud dan tujuan si pengarang. Semiotika memiliki peran yang sangat penting dalam mengkaji karya sastra. Selain itu, semiotika juga memiliki relasi/hubungan yang berpengaruh terhadap kehidupan sosial. Hal itu diperjelas oleh Andalas (2017: 41) terkait hubungan tanda yang berpengaruh di kehidupan sosial yang menjadikan system tanda sebagai bagian dari aturan sosial yang berlaku dikehidupan masyarakat. Dijelaskan juga jika tanda dan kehidupan sosial memiliki keterikatan yang amat dalam seperti benalu dengan inangnya.

Prinsip teori semiotika pada dasarnya berpengaruh terhadap kehidupan sosial dan menggunakan bahasa yang biasa digunakan didalam keseharian masyarakat. Bahasa keseharian yang dimaksudkan memiliki bermacam-macam tanda yang berupa tanda dalam sebuah peristiwa yang memiliki kesamaan makna (Andalas, 2017: 42). Oleh karena itu, semiotika tak luput dari pemaknaan di kehidupan sehari-hari masyarakat yang didalamnya terselubung berbagai makna yang sulit sekali terungkat dan masih terselubung sehingga mengharuskan para peneliti menguak kembali makna-makna yang berperan penting bagi masyarakat.

\section{KAJIAN TEORI}

Pendekatan yang digunakan dalam meneliti karungut Antang Ngambun Dayak Ngaju ini adalah pendekatan semiotik. Teori yang digunakan dalam mengkaji Karungut Antang Ngambun Dayak Ngaju yaitu teori semiotik yang dicetuskan Ferdinand De Saussure. Teori semiotik ini mempunyai peran menemukan suatu relasi yang berhubungan dengan tanda yang terdapat dalam kehidupan sosial didalam masyarakat. Tanda yang dimaksud ialah suatu tanda yang terdapat didalam karya sastra yang akan diteliti yang memiliki hubungan dalam meneliti makna yang terdapat didalamnya. Hal ini dijelaskan oleh De Saussure (dalam Akram, 2018 :9) yang 
menyatakan bahwa semiotik dibagi menjadi dua bagian yang didalamnya berupa penanda (Signifier) dan pertanda (signified). Pertanda yang dimaksudkan berupa bentuk/wujud fisik dalam karya sastra sedangkan pertanda yang dimaksudkan yaitu pengungkapan suatu makna yang dapat dilihat melalui konsep, fungsi dan nilai-nilai yang terkandung didalam karya sastra tersebut.

Asumsi yang terkait dengan pendekatan semiotik yang digunakan dalam mengkaji karungut Antang Ngambun yaitu pendekatan semiotik yang menjelaskan bahwa kajian yang diterapkan dalam suatu karya sastra meliputi sistem tanda yang menghubungkan makna serta nilai-nilai yang terkandung untuk dipahami melalui sebuah proses interpretasi terhadap kerangka berfikir yang didapatkan dalam karya sastra (Ambarini dan Umaya, 2010: 18). Tanda yang dimaksudnya dalam karya sastra ialah tanda yang bisa berupa kata yang dapat menunjukkansesuatu hal didalam teks, bisa juga dapat dikatakan sebagai kata kunci yang dapat menguak maksud dan tujuan dari sebuah karya sastra yang diteliti yang biasa disebut dengan mengungkapkan makna yang terkandung di dalamnya.

Teori semiotik sangat tepat digunakan dalam kajian ini karena teori ini akan membantu dalam menjelaskan masalah penelitian yang terdapat dalam Karungut Antang Ngambun yang merupakan puisi lama dari daerah Kalimantan yang berasal dari masyarakat Dayak Ngaju yang merupakan penduduk asli didaerah tersebut. Peneliti akan mengkaji secara mendalam setiap bait dari karungut berupa makna-makna dari petuah yang disampaikan didalam karungut tersebut. Semua itu akan diintrepretasikan lebih lanjut agar masyarakat paham akan kehidupan dahulu yang tidak serta merta mudah seperti sekarang ini. Mengajarkan bahwa hidup itu tidak akan bisa seperti sekarang jika tanpa perjuangan mereka dimasa lampau yang membuat anak cucunya hidup dengan serba praktis seperti sekarang ini. Teori semiotik itu sendiri berbicara tentang mengungkap makna yang berupa tanda dari sebuah karya sastra. Hal ini diperkuat dengan adanya tanda maka manusia bisa berfikir dan berkomunikasi satu sama lain. Manfaat tanda yang paling sering digunakan yaitu sebagai tanda visual yang bersifat non verbal yang terdiri dari unsur-unsur yang sangat mendasar berupa garis, warna, bentuk, komposisi, dan sebagainya (Istanto, 2000:114).

\section{METODE PENELITIAN}

Jenis penelitian yang digunakan dalam penelitian Karungut Antang Ngambun ini adalah Fenomenologi. Jenis penelitian Fenomenologi menggunakan pengalaman mengenai fenomenafenomena yang dialami seseorang atau sekelompok masyarakat sebagai informasi. Dalam hal ini pengalaman menganai fenomena terarah pada sosok manusia yang berubah menjadi elang dalam kepercayaan masyarakat Dayak. Pendekatan yan digunakan adalah Semiotika. Teori yang digunakan adalah teori Semiotik yang dikemukakan oleh Ferdinand De Saussure.

Data yang digunakan dalam mengkaji Karungut Antang Ngambun ini berupa kutipan kutipan syair yang dianggap mengandung simbol-simbol kebudayaan. Sumber data utama untuk mendapatkan syair Karungut Antang Ngamun ini adalah Sdr. Fhani Agus Setiawan selaku masyarakat asli Dayak Ngaju yang bertempat tinggal di Jl. Jendral Sudirman KM. 3,5 Sampit, Kalimantan Tengah. Setelah itu, proses penerjemahan lirik, dibantu oleh Sdri. Nurhasanah yang juga masyarakat asli Dayak Ngaju yang bertempat tinggal di Gang Garuda, Bagendang, Sampit, Kalimantan Tengah. Narasumber ini dipilih sebab dianggap mengetahui dan memahami mengenai kebudayaan masyarakat Dayak Ngaju dan Karungut Antang Ngambun. Pemilihan narasumber ini juga berdasar pada pemahaman Narasumber terhadap bahasa Dayak Ngaju yng saat ini sudah mulai langka penggunanya. 
Instrumen yang digunakan dalam penelitian ini berupa Telepon Genggam sebagai media menggali informasi dari narasumber. Penggunaan Telepon Genggam dilakukan sebab dirasa paling efektif, mengingat jarak yang ditempuh jika harus bertatap muka langsung sangat jauh. Pengumpulan data dilakukan dengan beberapa tahap yakni (1) mengajukan pertanyaan berupa syair lengkap Karungut Antang Ngambun pada narasumber pertama. (2) mengajukan pertanyaan mengenai kehidupan dan budaya masyarakat Dayak Ngaju. (3) mengajukan pertanyaan mengenai isi kandungan Karungut Antang Ngambun. (4) mengajukan pertanyaan mengenai arti atau terjemahan dari Karungut Antang Ngambun pada narasumber kedua. Data mengenai pertanyaan 1-3 diberikan oleh narasumber pertama (Fhani Agus Setiawan) berupa Audio, sedangkan data mengenai pertanyaan nomor 4 yang didapat dari narasumber kedua (Nurhasanah) berupa foto yang berisiskan tulisan tangan narasumber mengenai arti dari isi Karungut Antang Ngambun. Pertanyaan yang diajukan peneliti dijawab singkat dan tidak terlalu panjang, mengingat narasumber memiliki kegiatan yang cukup padat. Semua hasil komunikasi disimpan dalam telepon genggam sebagai data.

Dalam proses analisis data, dilakukan beberapa tahap untuk mendapatkan hasil, yakni (1) Audio Karungut Antang Ngambun diubah ke dalam bentuk transkrip dan diulang-ulang untuk memastikan bahwa yang dituliskan sudah sesuai. (2) Setelah berbentuk traskrip maka akan dilakukan penerjemahan kedalam bahasa Indonesia. Dalam hal ini peneliti meminta bantuan kepada salah seorang masyarakat Dayak. (3) dilakukan pengelompokan berdasarkan simbolsimbol yang digambarkan dalam karungut Antang Ngambun. Pengecekan keabsahan data dalam penelitian ini menggunakan teknik triangulasi sumber data dan teori. Dilakukan pula diskusi teman sejawat dan ahli. Dalam hal ini teman sejawat memiliki peran sebagai partner diskusi, sedangkan diskusi bersama ahli dilakukan bersama Dosen pembimbing.

\section{HASIL PENELITIAN}

Dalam masyarakat Kalimantan, Karungut difungsikan sebagai sarana hiburan dan penyampaian nasihat dan kepercayaan yang dianut dalam masyarakat. Bagi masyarakat Dayak sosok Pangkalima burung adalah sosok yang agung. Dalam masyarakat Dayak, Antang atau Elang adalah sosok dewa penjaga tanah Kalimantan. Dalam karungut Antang Ngambun ini dinceritakan mengenai sosok tetua adat atau lebih sering disebut Dulah yang memiliki sifas welas asih, berbudi baik dan tangguh pantang menyerah. Sosok Dulah ini lah yang akhirnya memiliki putra yang tampan dan memiliki watak seperti sang ayah. Anak itulah yang kelak menjadi elang. Masyarakat Dayak sangat mengagumi sosok panglima ini karena kesaktian dan sikap bijaksananya. Mengenai karungut Antang Ngambun ini akan dijelaskan lebih mendalam pada ulasan berikut. Semiotik menurut De Saussure (dalam Akram, 2018 :9) dibagi menjadi dua bagian yang di dalamnya berupa penanda (Signifier) dan pertanda (signified). Pembahasan mengenai hal tersebut akan diulas pada pemaparan dibawah ini. Berikut adalah Syair Karungut Anang Ngambun beserta arti.

\begin{tabular}{|l|l|}
\hline \multicolumn{1}{|c|}{ Karungut Antang Ngambun } & \multicolumn{1}{c|}{ Arti } \\
\hline Antang Ngambun & Anak sang Elang \\
Sahelu bara palampang kesah & Sebelum aku bercerita \\
Balaku ampun je kula tundah & Meminta izin pada semua \\
Dulah huran tambakas lewu & Dahulu dulah orang yang dituakan di \\
Budi basara bahalap tutu & kampung \\
Dengan kalunen saraba tau & Budi pekertinya sangat baik \\
\hline
\end{tabular}


Kutak pander auh balemu

Huang sinde andau katika

Dulah batulak inyuhu sawa

Tege ije angat kamia

Mipen atei metu akan pangina

Dulah palus batulak mengan

Hayak hanjewu je limbah kuman

Tihin sawa jalatien bulan

Salenya mipen barang panginan

Dulah mananjung bilik balingau

Kumbang kurah je bahu lakau

Jatun ije metu je sundau

Dia katawan hamalem andau

Kanih kate je tanjung tetei

Nampayah andau jadi halemei

Pehe angat je huang atei

Jalan buli dia baretei

Dulah mananjung sambil manggayar

Kakaput andau je sasar miar

Pasuruh ije lunuk bajangkar

Hete iye palus basandar

Dulah basandar je sambil munduk

Melai hunjun je uhat lunuk

Isin sipet hete inyucuk

Dia betiruh tuntang mangantuk

Sadang jadi kutahi hete

Hining kahabut kalunen are

Pander karas ureh tatawe

Kilau je hanjak angat pangkeme

Dulah palus tengak tangera

Manggau auh je kutak bata

Bara hete hining suara

Mantehau uluh je aka umba

Hete ewen tinai hakutak

Mangguang sawan je dulah manak

Mander kapehe puna karinah

Aku dia ulih batulak

Paingkuh pehe kilau imasak

Hayak dia ulih manggarak

Tacucuk tunggul ije habisak

Auh kutak ewen te benyem

Marak andau je kaput pijem

Sakira jadi je bentuk alem

Pengkeme dulah paham badarem

Bentuk alem jadi mahalau

Mahining tinai auh mantehau

Baya hamauh je bara kejau

Anak te kua hatue jagau
Sikapnya baik dengan semua orang

Tutur bahanya lemah lembut

Ketika disuatu hari

Dulah pergi diminta istri

Ada sesuatu yang diinginkan

Ingin makan hati binatang

Dulah bergegas pergi berburu

Pagi-pagi seusai makan

Istrinya hamil sudah sembilan bulan

Ada sesuatu yang diinginkan untuk

dimakan

Dulah berjalan sambil melihat sekitar

Kesana kemari dia menari

Tidak satu pun dia dapat

Tidak sadar hari sudah malam

Kesana kemari dia berjalan

Melihat hari sudah sore

Sakit sekali rasa hati

Perjalanan pulang tidak menentu

Dulah berjalan sangat pelan

Merasa hari terus berganti

Dia bertemu satu pohon besar

Di situ dia duduk bersandar

Dulah duduk sambil bersandar

Diatas akar pohon besar

Hati terasa tertusuk sumpit

Tidak bisa tidur walau mengantuk

Sudah lama dia ditempat itu

Dia mendengar suara riuh

Berbicara lantang dan nyaring

Nampak sangat bahagia

Dulah langsung melihat sekitar

Mencari darimana asal suara itu

Terdengar suara dari satu arah

Memanggil orang hendak ikut

Disitulah mereka berangkat

Menemui istri Dulah yang melahirkan

Dia bicara sangat kesakitan

Aku tidak bisa berangkat

Kakiku sakit seperti di tusuk-tusuk

Sama sekali tidak bisa digerakan

Tertusuk kayu sampai sobek

Mereka tidak berbicara lagi

Karena hari sudah gelap sekali

Sekiranya sudah tengah malam

Dulah merasa demam

Tengah malam sudah berlalu

Terdengar suara orang memanggil 


\begin{tabular}{|c|c|}
\hline 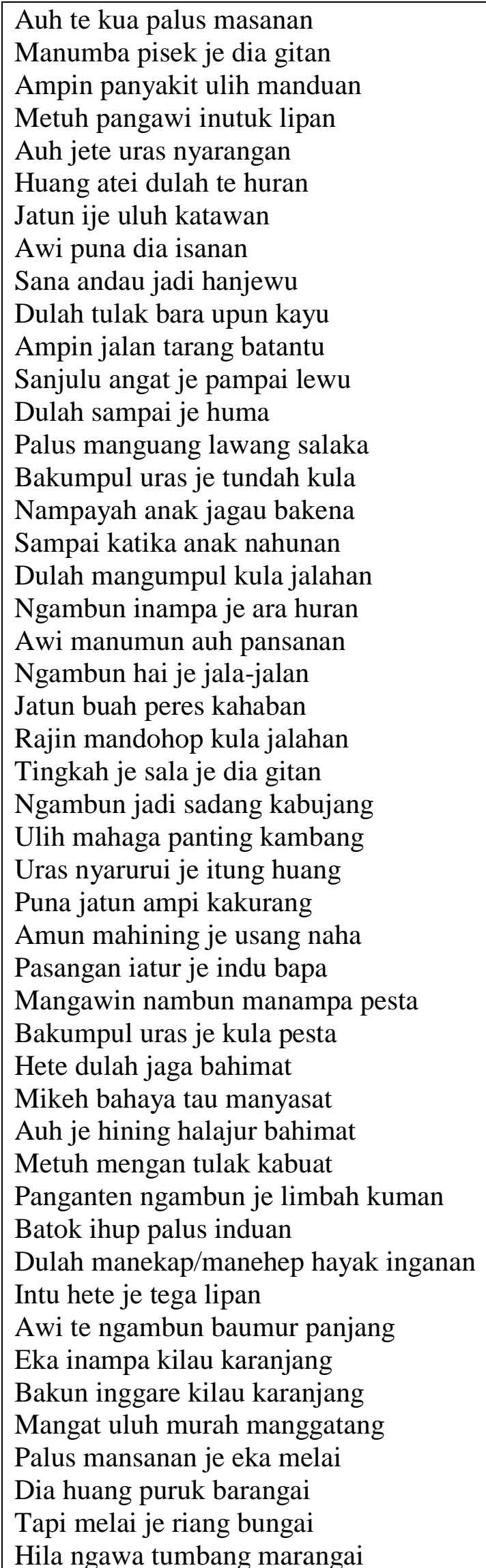 & $\begin{array}{l}\text { Suara dari kejauhan } \\
\text { Seorang anak laki-laki } \\
\text { Seperti suara orang yang berkata-kata } \\
\text { Menyahut suara yang tidak terlihat } \\
\text { Seperti penyakit yang sembuh } \\
\text { Seperti hanya digigit serangga } \\
\text { Seperti itu dia bersarang } \\
\text { Di dalam hati Dulah dahulu } \\
\text { Tidak satu orang pun tau } \\
\text { Karena dia tidak pernah cerita } \\
\text { Ketika hari sudah pagi } \\
\text { Dulah beranjak dari pohon } \\
\text { Karena jalan sudah terlihat terang } \\
\text { Begitu cepat sampai kampung } \\
\text { Dulah sudah sampai rumah } \\
\text { Segera menuju pintu } \\
\text { Berkumpul semu sanak-saudara } \\
\text { Melihat anak laki-laki yang tampan } \\
\text { Sampai ketika anak didoakan } \\
\text { Dulah mengundang sanak-saudara } \\
\text { Ngambun dibuatkan sebuah nama dahulu } \\
\text { Sesuai dengan pesan } \\
\text { Agar saat ngambun besar } \\
\text { Tidak akan sakit-sakitan } \\
\text { Rajin membantu sanak saudara } \\
\text { Perbuatan yang sudah tidak terlihat } \\
\text { Jika kelak dewasa } \\
\text { Bisa menjaga kehormatan } \\
\text { Semua yang di dalam ruangan } \\
\text { Tidak ada kekurangan } \\
\text { Jika mendengar yang sudah-sudah } \\
\text { Pasangan diatur oleh ibu bapak } \\
\text { Menikahkan anak dengan pesta } \\
\text { Berkumpul semua keluarga berpesta } \\
\text { Saat itu Dulah berjaga-jaga } \\
\text { Takut bahaya yang menyesatkan } \\
\text { Seperti yang pernah didengar } \\
\text { Saat pergi berburu seorang diri } \\
\text { Pengantin baru saja selesai makan } \\
\text { Mengambil gelas untuk minum } \\
\text { Dulah langsung membuang } \\
\text { Didalamnya ada binatang } \\
\text { Karena itu ngambun berumur panjang } \\
\text { Tempat dibuat seperti keranjang } \\
\text { Daun di ayunan seperti keranjang } \\
\text { Agar mudah diangkat } \\
\text { Langsung memberitahukan tempat } \\
\text { tinggal }\end{array}$ \\
\hline
\end{tabular}


Hete ngambun palus ihaga

Tuntang inampa je eka pasah

Kalute gawin je kula tundah

Andau harian tau manuah

Telu bulan je ngambun hete

Babulu antang je pai lenge

Anak esu puna nanture

Narai sebab taluh kalute

Tapi ngambun tege manarang

Akan karen garing tarantang

Ela hengan je itung huang

Aku tuh kareh manjadi antang

Baya huang bulan kauju

Tikas te ketun manyenguk aku

Mansanan akan je anak esu

Bele ketun karas manggau

Aku tuh gaib manjadi antang

Mansanan akan je kula nduang

Manabur behas bahenda bahandang

Amun itehau aku mangguang

Pelai ku palapas hila gantau

Mangat jete manjadi suntu

Amun ketun mantehau aku

Uka dia tau kaliru

Dia baya je jaman usang

Wayah jetuh tatap ingganang

Eweh bewei tau manimang

maManumun angat je itung huang

Antang intehau huang kapakat

Amun tege taluh manyasat

Ukat ie je tau mawat

Nyarurui itung malalus niat

Kalute saritan je jaman usang

Tege kalunen manjadi antang

Kesah nyata dia ingaran

Haranan ulu baumur panjang

Tikas tuh helu sarita lampang

Paramisi dengan patahu antang
Tidak diletakan sembarang tempat

Tetap ditempat yang sangat bagus

Arah hilir tumbang manggarai

Disitulah ngambun selalu dijaga

Sekalian membangun rumah

Seperti itu keluarga membantu bekerja

Suatu saat bisa beruntung

Tiga bulan ngambun disitu

Berbulu elang di sekujur tangan

Anak cucu memang melihatnya

Apa sebabnya semua itu

Tapi ngambun memiliki cahaya

Untuk semua yang ada

Janganlah heran di dalam hati

Aku ini nanti menjadi elang

Hanya saat bulan ke tujuh

Hanya saat itulah kalian menjenguk aku

Beritahulah anak cucu

Agar kalian tidak terlalu mencari

Aku ini gaib/menghilang menjadi elang

Beritahukanlah kepada sanak saudara

Untuk menabur beras kuning dan merah

Kalau dipanggil aku datang

Aku tinggali sayap sebelah kanan

Supaya itu menjadi contoh

Jika kalian memanggil aku

Agar nanti tidak keliru

Tidak hanya zaman dahulu

Saat ini pun tetap dikenang

Siapa saja bisa menimang

Menurut rasa dan perasaan

Elang dipanggil dalam kebersamaan

Kalau ada sesuatu yang menyesatkan

Agar dia bisa menjaga

Menyusuri diri dan malangsungkan niat

Seperti itulah cerita zaman dahulu

Ada manusia yang menjadi elang

Kisah nyata tidak dikarang

Karena orang merumur panjang

Kisah ini yang selalu muncul

Mohon izin pada sang elang

Teks syair tersebut merupakan petanda yang dimaksudkan oleh Ferdinand De Sausure. Dikatakan demikian karena pembahasan tersebut hanya menyuguhkan struktur luar dari Karungut Antang Ngambun, tanpa pemahaman mendalam terhadap makna tersirat yang terkandung didalamnya. Pembaca belum memahami apa maksud sebenarnya dari lirik-lirik yang ada. Oleh karena itu, dibutuhkan pemaknaan mendalam, yakni mengenai makna konotatif agar pembaca dapat memahami maksud sebenarnya pesan yang disampaikan. 
Proses terciptanya Karungut Antang Ngambun tidak berbeda dengan proses terciptanya Karungut pada umumnya, yakni berasal dari cerita para tetua desa atau tetua adat mengenai kepercayaan masyarakat Dayak dan petuah petuah mengenai kehidupan. Kisah-kisah dan petuah itu kemudian dilantunkan menjadi syair indah yang memiliki makna yang mendalam bagi masyarakat Dayak.

Sejak awal penciptaannya hingga saat ini Karungut Antang Ngambun tidak mengalami perubahan baik dari segi fungsi maupun dari segi isi. Hal itu karena sampai saat ini Karungut Antang Ngambun masih digunakan oleh masyarakat Dayak Ngaju sebagai hiburan rakyat, sarana memberi petuah, penanaman kepercayaan yang dianut nenek moyang, dan kesenian yang digunakan saat acara adat. Mengenai isi Karungut Antang Ngambun dikatakan tetap dan tidak berubah karena pada dasarnya seluruh lirik syair Karungut tidak pernah mengalami perubahan dari segi isi. Kemungkinan perubahan Karungut hanya pada alih bahasa dari salah satu sub bahasa dayak ke sub bahasa dayak lainnya. Hal itu dilakukan untuk memudahkan pemahaman masyarakat yang memiliki pemikiran yang sama walau berbeda sub suku Dayak. Contoh konkretnya mengenai kepercayaan pada sosok yang diagungkan oleh seluruh masyarakat Dayak dari berbagai sub suku yang ada yakni Pangkalima Burung. Sosok tersebut tergambar dalam Karungut Antang Ngambun yang menggunakan bahasa Dayak Ngaju, sub suku lain bisa mengalih bahasakan berdasarkan bahasa masing-masing dengan sedikit perubahan cara penyampaian menyesuaikan adat masing-masing namun tidak merubah dari isi Karungut Antang Ngambun berupa makna dan maksud penyampaiannya.

Simbol-Simbol Kebudayaan dalam Karungut Antang Ngambun Dalam karungut Antang Ngambun terdapat makna konotatif yang menyiratkan makna dalam simbol-simbol dalam tiap lariknya. Simbol-simbol yang ada dalam karungut tersebut tidak lepas dari pengaruh kehidupan masyarakat. Dalam hal ini simbol-simbol dalam Karungut Antang Ngambun berhubungan dengan keperayaan dan sifat yang dimiliki masyarakat Dayak, khususnya Dayak Ngaju. Mengenai makna konotatif dalam Karungut Antang Ngambun akan dibahas dalam pemaparan berikut.

\section{Simbol kelemah Lembutan}

Dalam karungut Antang Ngambun ini terdapat simbol kelemah lembutan. Simbol itu di gambarkan dengan penceritaan seorang pemimpin yang baik hati. Selain baik hati sosok yang diceritakan juga bertutur lemah lembut. Simbol kelemah lembutan tersebut dapat terlihat pada penggalan syair Karungut Antang Ngambun berikut.

\begin{tabular}{|c|c|}
\hline Bahasa Dayak Ngaju & Arti \\
\hline Dulah huran tambakas lewu & Dahulu dulah orang yang dituakan di \\
Budi basara bahalap tutu & kampung \\
Dengan kalunen saraba tau & Budi pekertinya sangat baik \\
Kutak pander auh balemu & Sikapnya baik dengan semua orang \\
& Tutur bahanya lemah lembut \\
\hline
\end{tabular}

Berdasarkan kutipan syair beserta artinya diatas, dapat dimaknai bahwa masyarakat Dayak Ngaju adalah sosok yang memiliki sifat baik terhadap semua orang. Hal itu tergambarkan dari sosok seorang pemimpin yang sangat dihormati dan sosok yang dituakan dalam masyarakat. Kedudukan yang disandangnya itu tidak membuat dia berbuat semaunya, dia selalu menjaga tuturannya terhadap orang lain. Tuturannya selalu lemah lembut pada siapa pun dia berbicara. Menurut informan masyarakat dayak memang seharusnya bertutur lemah lembut. Karena sosok yang diagungkan dan di yakini sebagai penjaga mereka, adalah sosok yang juga bertutur lembut.

\section{Simbol Kasih Sayang}

Didalam Karungut Antang Nagmbun juga berisi tentang simbol kasih sayang. Hal itu disimbolkan dengan sosok Dulah selaku tetua didesa. Dulah adalah sosok yang sangat menyayangi keluarganya. Simbol kasih sayang itu tergambar pada penggalan syair berikut: 


\begin{tabular}{|c|c|}
\hline Bahasa Dayak Ngaju & Arti \\
\hline & Ketika disuatu hari \\
Huang sinde andau katika & Dulah pergi diminta istri \\
Dulah batulak inyuhu sawa & Ada sesuatu yang diinginkan \\
Tege ije angat kamia & Ingin makan hati binatang \\
Mipen atei metu akan pangina & Dulah bergegas pergi berburu \\
Dulah palus batulak mengan & Pagi-pagi seusai makan \\
Hayak hanjewu je limbah kuman & Istrinya hamil sudah sembilan bulan \\
Tihin sawa jalatien bulan & Ada sesuatu yang diinginkan untuk \\
Salenya mipen barang panginan & dimakan \\
Dulah mananjung bilik balingau & Dulah berjalan sambil melihat sekitar \\
\hline
\end{tabular}

Dari penggalan syair tersebut nampak kasih sayang yang ditunjukan oleh sosok Dulah. Dia begitu menyayangi istrinya. Mendengar istrinya menghendaki sesuatu, Dulah segera untuk mencarikan apa yang diinginkan istrinya tersebut. Sikap yang digambarkan dialam Karungut Antang Ngambun ini menyiratkan makna seorang warga dayak harusnya penuh cinta kasih, memiliki rasa cinta yang besar sehingga selalu berusaha membahagiakan sosok yang dia cintai. Menurut informan selain sikap lemah lembut, masyarakat dayak memang seharusnya memiliki sifat kasih. Hal ini lagi-lagi tidak terlepas dari sosok yang diagungkan masyarakat, yang juga memiliki sifat kasih yang besar, terutama terhadap siapa saja yang dianggapnya saudara.

\section{Simbol Sikap Pantang Menyerah}

Selain mengandung simbol kelemah lembutan dan kasih sayang. Dalam karungut Antang Ngambun juga terdapat simbol sikap pantag menyerah. Simbol itu digambarkan dengan cerita seorang suami yang berburu mencari binatang untuk sang istri yang sedang hamil. Perburuan itu dilakukan dengan tanpa mengenal lelah dan tidak kenal hari. Simbol tersebut tergambar dalam penggalan syair berikut:

\begin{tabular}{|c|c|}
\hline Bahasa Dayak Ngaju & Arti \\
\hline Kumbang kurah je bahu lakau & Kesana kemari dia menari \\
Jatun ije metu je sundau & Tidak satu pun dia dapat \\
Dia katawan hamalem andau & Tidak sadar hari sudah malam \\
Kanih kate je tanjung tetei & Kesana kemari dia berjalan \\
Nampayah andau jadi halemei & Melihat hari sudah sore \\
Pehe angat je huang atei & Sakit sekali rasa hati \\
Jalan buli dia baretei & Perjalanan pulang tidak menentu \\
Dulah mananjung sambil manggayar & Dulah berjalan sangat pelan \\
Kakaput andau je sasar miar & Merasa hari terus berganti \\
& \\
& \\
\hline
\end{tabular}

Pengalan syair diatas nampak sorang pria yang sedang berburu untuk memenuhi hajat istrinya. Dia berburu tanpa mengenal lelah dan tanpa mengenal waktu. Penggalan syair diatas menyiratkan makna bahwa masyarakat Dayak adalah sosok yang memiliki jiwa pantang menyerah. Mereka adalah orang orang tangguh yang tidak akan berhenti hingga hajatnya terpenuhi. Menurut informan hal itu memang menjadi pedoman hidup masyarakat Dayak, namun tentu semua harus disesuaikan dengan keadaan dan kemampuan. Hal ini lagi-lagi tidak terlepas dari sosok spiritual masyarakat Dayak yakni Panglima Burung Pangkalima Burung. 


\section{Simbol Kepercayaan}

Dalam karungut Antang Ngambun terdapat simbol mengenai Kepercayaan masyarakat Dayak. Masyarakat Dayak memiliki sistem kepercayaan terhadap sosok yang diagungkan oleh masyarakatnya. Sosok yang dianggap sebagai pelindung dan panutan bagi masyarakat Dayak. Sosok tersebur adalah Pangkalima Burung. Simbol mengenai sosok Panggalima Burung dalam karungut Antang Ngambun ini terdapat pada penggalan syair berikut:

\begin{tabular}{|c|c|}
\hline Bahasa Dayak Ngaju & Arti \\
\hline Mansanan akan je anak esu & Beritahulah anak cucu \\
Bele ketun karas manggau & Agar kalian tidak terlalu mencari \\
Aku tuh gaib manjadi antang & Aku ini gaib/menghilang menjadi elang \\
Mansanan akan je kula nduang & Beritahukanlah kepada sanak saudara \\
Manabur behas bahenda bahandang & Untuk menabur beras kuning dan merah \\
Amun itehau aku mangguang & Kalau dipanggil aku datang \\
Pelai ku palapas hila gantau & Aku tinggali sayap sebelah kanan \\
Mangat jete manjadi suntu & Supaya itu menjadi contoh \\
Amun ketun mantehau aku & Jika kalian memanggil aku \\
Uka dia tau kaliru & Agar nanti tidak keliru \\
Dia baya je jaman usang & Tidak hanya zaman dahulu \\
Wayah jetuh tatap ingganang & Saat ini pun tetap dikenang \\
Eweh bewei tau manimang & Siapa saja bisa menimang \\
Manumun angat je itung huang & Menurut rasa dan perasaan \\
Antang intehau huang kapakat & Elang dipanggil dalam kebersamaan \\
Amun tege taluh manyasat & Kalau ada sesuatu yang menyesatkan \\
Ukat ie je tau mawat & Agar dia bisa menjaga \\
& \\
\hline
\end{tabular}

Dalam penggalan syair diatas mencaritakan mengenai sosok yang diagungkan masyarakat. Didalamnya juga diceritakan bahwa sosok yang diagungkan itu akan menjaga anak cucunya dari mara bahaya. Hal itu dapat dimaknai bahwa masyarakat Dayak memiliki sistem kepercayaan terhadap sosok Pangkalima Burung. Sosok yang diagungkan itu dipercaya selalu melindungi mereka masyarakat dayak yang menggangap diri mereka adalah anak cucu pangkalima burung. Masyarakat Dayak percaya bahwa sosok Pangkalima Burung akan hadir jika anak cucunya memanggilnya dalam keadaan susah. Menurut informan, masyarakat menyakini pangkalima burung adalah sosok penjaga tanah Kalimantan. Sosok itu memiliki sifat bijaksana, suka menolong, bertutur lembut, dan penuh cinta kasih. Sosok Pangkalima Burung hanya tidak suka jika anak cucunya diganggu. Jika anak cucunya diganggu maka sosok yang lemah lembut itu bisa menjadi sosok yang mengerikan. Hal itu salaras dengan pendapat Johnson \& Johnson (dalam Putri,2017:622) bahwa trust dibangun melalui perilaku mempercayai (trusting) dan dapat dipercayai (trustworthy). Masyarakat sangat meyakini sosok Pangkalima burung yang selalu mereka dengar dari cerita para orang tua mereka. Keyakinan itu selalu ditanamkan oleh orang tua masyarakat Dayak kepada anaknya.

\section{Simbol Budaya}

Simbol Budaya juga dicerminkan dalam karungut Antang Ngambun ini. Simbol itu tergambar dalam penggalan syair yang bercerita tentang kebudayaan yang dijalankan oleh masyarakat Dayak Ngaju. Penggalan syair tersebut adalah sebagai berikut: 


\begin{tabular}{|c|c|}
\hline Bahasa Dayak Ngaju & Arti \\
\hline Bakumpul uras je tundah kula & Berkumpul semu sanak-saudara \\
Nampayah anak jagau bakena & Melihat anak laki-laki yang tanpan \\
Sampai katika anak nahunan & Sampai ketika anak didoakan \\
Dulah mangumpul kula jalahan & Dulah mengundang sanak-saudara \\
Ngambun inampa je ara huran & Ngambun dibuatkan sebuah nama dahulu \\
Awi manumun auh pansanan & Sesuai dengan pesan \\
Ngambun hai je jala-jalan & Agar saat ngambun besar \\
Jatun buah peres kahaban & Tidak akan sakit-sakitan \\
& \\
\hline
\end{tabular}

Penggalan syair diatas menggambarkan keadaan yang ramai. Berkumpulnya sanak saudara sebagai bentuk syukur atas kelahiran seorang anak. Dalam penggalan syair diatas dapat dimaknai bahwa masyarakat Dayak juga memiliki kebudayaan dalam menyambut atau bersyukur atas kehadiran seorang anak ke dunia. Prosesi itu dilakukan untuk memberi nama terhadap anak yang telah lahir. Sampai saat ini masyarakat masih melakukan adat ini. Setiap bayi yang lahir akan diberi nama dengan diiringi prosesi memanjatkan doa dan pengharapan terhadap keberlangsungan hidup si bayi. Nilai-nilai kebudayaan tersebut masih dijaga oleh masyarakat. Dengan demikian, hal itu selaras dengan pendapat yang dikemukakan (Marwati dan Anton, 2015:1) bahwa pemeliharaan dan pembinaan sastra daerah berfungsi agar masyarakat mengetahui bahwa sastra daerah itu tidak semata-mata berisi khayalan, tapi juga mempunyai nilai budaya yang di dalamnya termasuk nilai moral dan nilai kehidupan yang berguna bagi masyarakat. Artinya hal yang dilakukan oleh masyarakat Dayak merupakan bentuk dari proses pemeliharaan nilai-nilai dalam budaya mereka.

\section{SIMPULAN}

Karungut Antang Ngambun adalah salah satu kebudayaan masyarakat Kalimantan Tengah. Isinya menceritakan mengenai kelahiran sosok yang diagungkan masyarakat Kalimantan. Sosok itu adalah Pangkalima burung. Sosok itu dipercaya sebagai manusia yang berubah menjadi seekor burung. Selain keahiran, karungut Antang Ngambun juga mengisahkan mengenai sosok dan sikap keluarga dari sang Pangkalima Burung. Sikap yang selanjutnya ikut dimiliki sang Antang.

Masyarakat Kalimantan memercayai bahwa sosok Pangkalima Burung adalah sosok yang menjaga mereka dari segala mara bahaya, dan akan datang apabila anak cucunya yakni masyarakat Dayak memerlukan bantuannya. Kepercayaan itu masih dipegang sampai saat ini oleh masyarakat.

Selain menjadi sosok penjaga, Pangkalima Burung juga menjadi sosok panutan bagi masyarakat Kalimantan. Sosoknya dianggap sebagai bentuk representasi dari masyarakat dayak. Masyarakat meyakini bahwa pangkalima Burung memiliki sifat rendah hati dan selalu bertutur lembut. Dia juga diyakini sebagai sosok yang penuh cinta kasih. Jika dia melakukan sesuatu maka akan diselesaikan dengan baik, tidak akan menyerah dan berhenti. Dengan kata lain Pangkalima Burung juga sosok yang pantang menyerah.

Sifat dan sikap Pangkalima Burung menjadi panutan bagi seluruh masyarakat dayak. Semua itu terekam dalam suatu karya yang bernama karungut Antang Ngambun. Makna yang terkandung dalam karungut Antang Ngambun inilah yang membuatnya dijadikan bahan 
pembelajaran mengenai moral oleh masyarakat Dayak. Selain itu, alasan itu pula lah yang membuat karungut dihadirkan dalam upacara adat Dayak. Sebenarnya semua karungut mendapat fungsi dan kedudukan yang sama. Yakni sebagai sarana hiburan dan berpetuah. Namun, sedikit berbeda dengan karungut Antang Ngambun karena didalamnya juga terkandung informasi mengenai sosok yang diagungkan oleh masyarakat Dayak yakni Pangkalima Burung.

\section{Daftar Pustaka}

Akram, Mohammad. 2018. Mantra Bagi Masyarakat Melayan Suku Bajo Desa Saur Saibus Kecamatan Sapeken Kabupaten Sumenep. Skripsi. Hal: 9.

Ambirini dan Nazia Maharani Umaya. 2010. Semiotika Teori dan Aplikasi Pada Karya Sastra. Hal: 18.

Andalas, Eggy Fajar. 2017. Sastra Lisan: Kajian Teori dan Penerapannya Dalam Penelitian.

Kelompok Intrans Publishing.

Faridah Siti. 2016. Nilai-Nilai Budaya Dalam Sastra Lisan Madihin Banjar. Jurnal Seminar Nasional Pergerakan Sastra Indonesia di Eropa dan Implementasi Pendidikan di Indonesia.

Istanto, Freddy. 2000. Rajutan Semiotika Untuk Sebuah Iklan Studi Kasus Iklan Long Beach. Jurnal Desain Komunikasi Visual

Marwati dan Anton. 2015. Ungkapan Tradisional Dalam Upacara Adat Perkawinan Masyarakat Bajo Di Pulau Balu Kabupaten Muna Barat. Jurnal Humanika. Vol. 3, No. 15.

Putri Nina Aggita. 2017. Kepercayaan (Trust) Masyarakat Suku Dayak Benuaq Pada Pengobatan Tradisional Belian(Studi Kasus Di Desa Resak, Kutai Barat). Ejournal Psikologi. Vol. 5, No. 3, hlm 621-629.

Satriana Eka. 2015. Makna Ungkapan pada Upacara Perkawinan Adat Bulukumba di Desa Buhung Kec. Bontotirto Kab.Bulukumba. Jurnal Humanika. Vol. 3, No. 15.

Sari, Gisca Gaprita. 2014. Analisis Tanda Verbal Iklan Smartphone NTT Docomo di Media Televisi Jepang : Kajian Semiotika. Japanology. Vol. 2.

Taruna Jenny Andany. 2016. Fungsi Dan Bentuk Penyajianinstrumen Musikkarungut Di Kalimantan Tengah. Jurnal Skripsi.

Tinarbuko, Sumbo. 2003. Semiotika Analisis Tanda Pada Karya Desain Komunikasi Visual. Jurnal Desain Komunikasi Visual.

Wahyuni Erna. 2016. Membangun Karakter Anak Melalui Cerita Prosa Rakyat Berjenis Legenda: Pengenalan Sastra Lisan Dalam Pembelajaran Sastra Anakdi Perbatasan Kalimantan Utara. Jurnal Seminar Sastra Anak. 